\title{
Challenges for secondary education in Latin America
}

\section{Juan Carlos Tedesco}

Néstor López

International Institute

for Educational

Planning (IIEP)-UNESCO,

Buenos Aires

j.tedesco@iipe-buenosaires.org.ar

n.lopez@iipe-buenosaires.org.ar
In recent years, most Latin American countries have committed themselves, implicitly or explicitly, to achieving universal provision of a good-quality basic secondary education. Despite the diversity of the situations to be found in the region, it is possible to see that what this commitment means for each of these countries is having to cope simultaneously with educational deficiencies inherited from the past -primarily, incomplete coverage that leaves some adolescents outside the system- and the new challenges raised by the exigencies of change in the organization of work, culture and citizenship. The present article sets out by recognizing this "surfeit of demands" on education, and seeks to show some of the greatest dilemmas and tensions faced by policies to achieve good-quality, universal secondary education in the region. 


\section{I}

\section{Introduction}

Diagnostic analyses of secondary education in Latin America agree in identifying both the crucial importance of this level for social development and the personal destiny of individuals, and the particularly critical situation it is now in as regards both functioning and outcomes. It was in this context that most of the region's countries began to implement changes in their secondary education systems in the 1990s. Perusal of national documents dealing with these reforms shows that the objectives being aimed at are quite ambitious, both quantitatively and qualitatively. They can be summarized as the universalization of a good-quality basic secondary education, with the idea of good quality including training in the new skills needed to operate effectively as citizens and producers in a society characterized by complex and constantly shifting requirements.

The gap between the ambitious objectives proposed and the critical situations from which the countries are setting out is very large. Although there are major differences among and within countries, the region as a whole is still having to cope with major educational deficiencies inherited from the past. The specificity of the current situation, furthermore, is that this legacy is having to be dealt with in conjunction with the new challenges posed by changes in the organization of work, culture and citizenship. In seeking to explain problems and decide on strategies for change, the importance of this new context cannot be underestimated. To put it briefly, at a time when society is being profoundly transformed at every level, the countries of the region are having to cope simultaneously with the deferred educational demands of lower-income sectors and with calls to satisfy the new demands of sectors already catered to by the system. It is not just a case, then, of having to heed the demands of sectors that have not so far had access to a stable service. Demands are also coming from sectors that already have access to such a service, and are now insisting that it be reformed.

In situations like this, where there is a surfeit of demands, it seems inevitable that decisions will have to be taken that meet some needs by postponing the satisfaction of others. Since all the demands are urgent and legitimate, no sector is prepared to defer to others.
The struggle for scarce resources thus takes on characteristics that are not very rational from the point of view of general, long-term interests. The perils of this situation are well known. The most obvious and visible one is that decisions about priorities and resource allocation are settled in favour of those who are best able to express demands and exert pressure for them to be met. Another peril, which is less visible but real enough in several of the region's countries, is that sectors already catered to by the system will react negatively to policies designed to promote greater access and participation for the excluded. This negative reaction tends to manifest itself in a low opinion of the importance of these efforts and criticism of their lack of impact on quality or, from a more structural viewpoint, in the abandonment of the public education system and the expansion of private schools, where most of the educational investment of the better-off sectors goes.

As a result, the gap between the objectives proposed and the decisions taken tends to widen, giving rise to a socially perceived phenomenon of dissociation whereby the objectives set forth in public do not tally with what is happening in practice. ${ }^{1}$

On the basis of these general considerations, the sections that follow try to show some of the greatest dilemmas and tensions besetting policies to universalize good-quality secondary education. Section II provides data that give an idea of the scale of the main macroeducational challenges in Latin America and the differences that exist both among and within countries. Section III analyses the main tendencies of the educational reforms now being implemented in the region for this level of education, and section IV sets forth some conclusions regarding policy orientations for the future.

\footnotetext{
${ }^{1}$ This phenomenon, characteristic not only of educational policies but of public policy in general, is a root cause of the weakness in the region's democratic processes. Discussion of this subject is becoming topical again (Nun, 2000).
} 
II

\section{Is the easy part of educational expansion over?}

\section{Latin America and the developed countries}

The educational challenges facing Latin America differ depending on whether the goals being contemplated relate to primary or secondary education. In primary education, the region overall, and the great majority of individual countries, have already achieved the ambition of universal coverage. If tendencies in the region as a whole over the last 30 years are observed, it transpires that, after a brief drop in the mid-1970s, the gross primary school enrolment rate shows a gently upward trend, at values slightly in excess of $100 \%$ (figure 1).

If we compare Latin America with the developed countries, we find that the tendency is similar, although for the latter the line is closer to $100 \%$, something that may be interpreted as being the result of a lower incidence of over-age situations owing basically to their low repetition indices. Now that the goal of universal primary schooling has been achieved in many countries, priority is being given to the objectives of equity in access to good-quality education, and of greater internal efficiency.

The situation is far more complex, on the other hand, when we look at school enrolment rates at the secondary level. Figure 2, which synthesizes trends in the region as a whole, shows that while secondary school enrolment rates have risen significantly over the last 30 years, and particularly during the 1990s, even now over a third of young people of secondary school age are not enrolled.

The comparison between Latin America and the developed countries shows the region achieving the coverage levels that the developed countries had in 1970 by the year 2000. This deficit is having to be dealt with, however, in a context that is significantly different from that of three decades ago, particularly as regards the tendency for social goods and services to become universalized. We shall return to this point in section III.

\section{The diversity of national situations}

Considering Latin America as a single whole obviously means ignoring the great diversity of situations in the region. Strictly speaking, every country should be analysed on its own to discover the specific way in

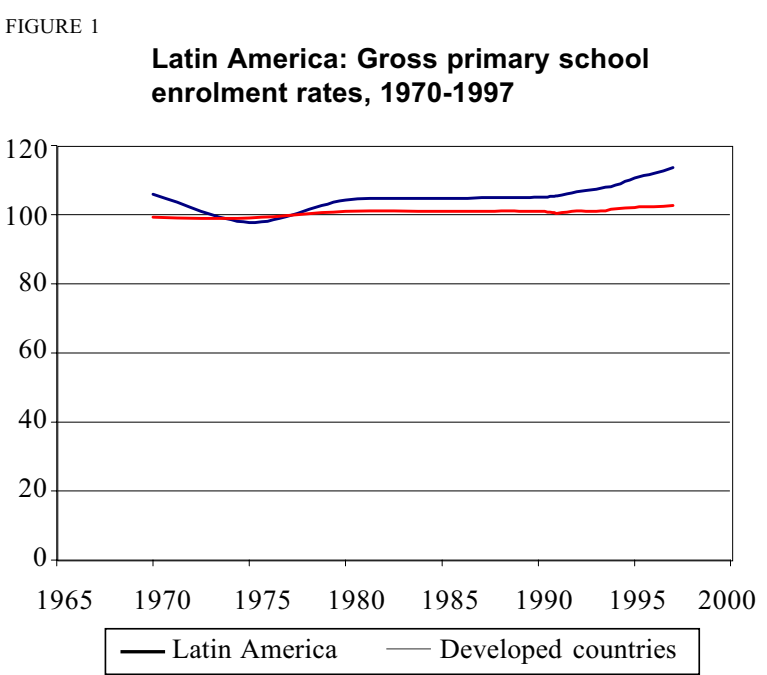

Source: Prepared by the authors on the basis of UNESCO data.

FIGURE 2

Latin America: Gross secondary school enrolment rates, 1970-1997

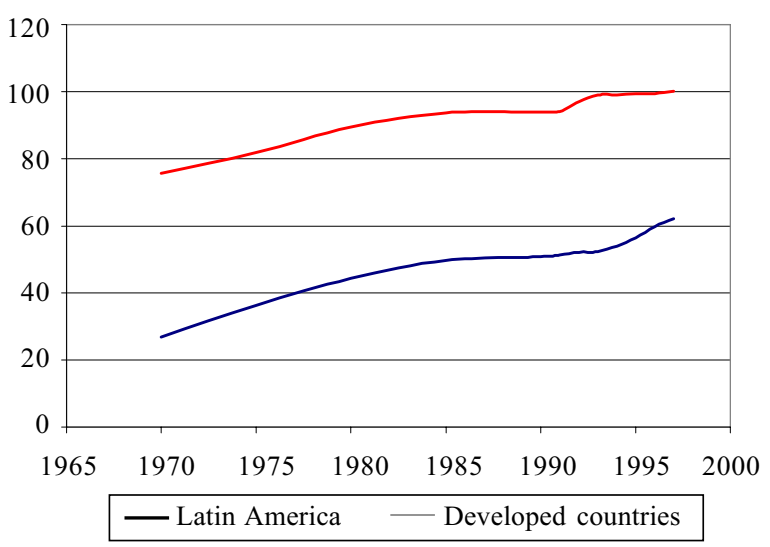

Source: Prepared by the authors on the basis of UNESCO data.

which the sociodemographic, political, economic, ethnic and cultural aspects mesh with one another so that policies to achieve universal schooling in a goodquality secondary system can be devised. Nonetheless, the information available on the countries of Latin America does reveal certain recurrent situations that 
suggest there is scope for attempting an organizing typology of diversity.

What is proposed here, then, is a country classification exercise to identify groups that are reasonably homogenous within themselves and distinct from one another. The first factor that needs to be considered in this classification process is the demographic profile of each country, as this obviously facilitates or hinders the achievement of school enrolment targets. Two features of what is known as a "traditional" demographic profile -high population growth rates and a high proportion of the population living in rural areas- are a particular challenge in the task of extending coverage towards universality.

A second factor is the level of gross per capita product, as a proxy for each country's degree of economic development. Underlying this choice of indicator is the fact that, in absolute terms, higherincome countries have greater public- and private-sector resources available to invest in education. ${ }^{2}$

Using this approach we can basically identify four groups of countries in Latin America, situated the length of an axis that runs from highly urbanized countries with very low population growth and high incomes (by Latin American standards) to countries with a fundamentally rural profile, high population growth and very low incomes. These groups are as follows:

i) High-income countries with a modern demographic profile. This set comprises the three countries of the Southern Cone: Argentina, Chile and Uruguay. Demographically, these are the countries with the lowest population growth rates and the highest concentrations of inhabitants in urban areas. They are also the three countries with the highest per capita gross domestic product in Latin America.

ii) Middle-income countries at an advanced stage of the demographic transition. This category includes six countries: Brazil, Costa Rica, Mexico, Panama,

\footnotetext{
2 The causal relationship between a country's demographic and economic characteristics and the extension of the education system is neither linear nor straightforward. While the impact of these factors on the extension of the education system is considered, the converse is equally significant: greater access to education creates a better environment for the development of practices that affect the rate of population growth and its geographical distribution, and also helps economic development. Secondly, there is a strong association between demographics and the economy. In point of fact, there is no country in Latin America with a high per capita income level and a traditional demographic profile, or with a modern demographic profile and a low level of income.
}

Peru and Venezuela. While demographically these countries are quite similar to the three named above, their per capita GDP averages only half theirs. ${ }^{3}$

iii) Low-income countries just beginning the demographic transition. This third group contains Colombia, the Dominican Republic, Ecuador, El Salvador, Guatemala and Paraguay. Demographically, these countries are in an intermediate situation. Some $40 \%$ of their population is in rural areas, and they are under severe pressure from rapid population growth. Incomes there average about half those of the previous group.

iv) Very low-income countries with a traditional demographic profile. This last group is formed by Bolivia, Haiti, Honduras and Nicaragua, countries whose per capita GDP is only a third of the previous group's. Over half their population lives in rural areas, and demographic growth rates are very high.

To construct this typology, use was made of a classificatory analysis of hierarchical conglomerates, the basis for this being the measurement of similarities and differences among cases in respect of the variables proposed. Exercises of this type always raise questions about the validity of one or another country's inclusion in each group, and it is possible that there may be doubts in some cases. ${ }^{4}$ Still, irrespective of how justifiable a particular country's inclusion in one or another category of this typology is, the value of the exercise consists in showing that there is not one "Latin America" but several. $^{5}$

Table 1 gives a set of indicators summarizing the sociodemographic and educational profile of each of the groups described. A first aspect that offers a clue to the diversity of educational situations is the extent of adult illiteracy in each of them. While in group 1 countries only $4 \%$ of adults are illiterate, in group 4 the figure is $33 \%$.

\footnotetext{
${ }^{3}$ Simple average of the per capita GDP levels, in dollar terms, of the countries concerned.

${ }^{4}$ The boundary between groups 2 and 3 is relatively unclear. Peru appears in group 2 basically because of its demographic profile, while its per capita GDP would place it somewhere between the two. Colombia has population growth closest to that of group 2, a degree of urbanization close to the average for the two groups, and a group 3 level of GDP. ${ }^{5}$ Cuba has obviously been left out of this classification. Owing to the particular characteristics of its social and political system, Cuba has the demographic and educational features of the first group but a much lower per capita GDP. Nor have we included the Englishspeaking Caribbean countries, which merit separate analysis.
} 


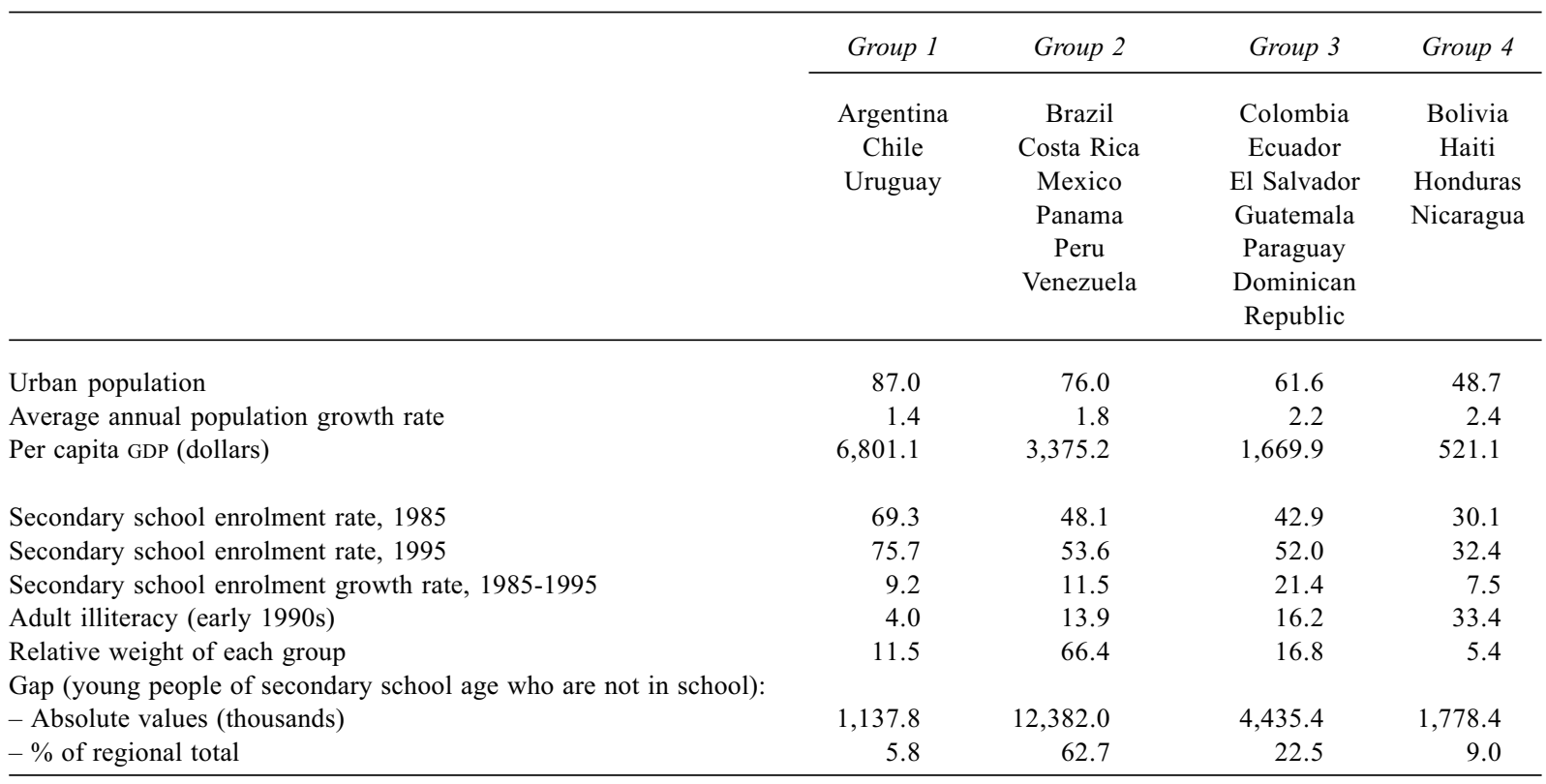

Source: Prepared by the authors on the basis of UNESCO data (1998).

Looking at secondary school enrolment levels in the mid-1980s, we find that the Southern Cone countries had the highest values and were well ahead of the other groups. Among these others, rates fall from one group to the next until in group 4 we find less than a third of all young people in intermediate education.

Over the period 1985-1995, we see a rise in secondary school enrolment rates in all cases, something that deserves special attention. Generally speaking, we know that growth processes follow a dynamic whereby the pace of improvement slackens as the indices approach their final value. In situations of low school attendance, for example, education forms part of what are known as the "soft areas" of social policy, i.e., those that are less resistant to change. As the coverage of demand increases, society as a whole has to make greater efforts and investments to continue advancing towards universal attendance. Thus, education gradually shifts into the category of what are known as "hard areas" of social policy (Kaztman and Gerstenfeld, 1990).

Analysis of the growth dynamic of secondary school enrolment rates during the period 1985-1995 sheds a great deal of light on what is happening in the region. The countries in group 1 , which have the highest rates, are the ones that show the lowest growth during the period, as the type of measures needed to expand coverage relate to more structural aspects of the education system. Groups 2 and 3 behave as would be expected from the considerations described, so that larger increases in school attendance rates in countries where these were lower to begin with (in this case, group 3) are leading over time to gradual upward convergence.

By contrast, the situation of the group 4 countries is highly critical from this point of view. As well as having the lowest levels of school attendance, these countries as a group also show the lowest relative growth in the period. The neediness of these countries undoubtedly acts as an obstacle to development of the education system, and this continues to hold them back so that they are unable to close the gap with the rest of the region.

\section{Heterogeneity within countries}

The educational situation varies not only among countries, however, but within them as well. From 
information presented in a World Bank document $(\mathrm{n} / \mathrm{d})^{6}$ on the educational situation of Latin America, it is possible to estimate the size of the disparities within eight of the region's countries as regards access to intermediate education during the first half of the 1990s, taking account of sex, socio-economic level and urban or rural residence.

Firstly, we can see in table 2 that the column for disparities by sex is the one whose values stay closest to 1. The countries with the largest disparities are El Salvador, where the male attendance rate is $15 \%$ higher than the female rate, and Honduras and Nicaragua, where the difference is about $10 \%$, this time in favour of females. In the cases of Chile, Costa Rica and Ecuador, there is virtually no noticeable difference in access to education by sex. From supplementary information we can state that these disparities are slightly greater in rural sectors, and among the poorest families.

The differences begin to be larger when we analyse the access opportunities of young people from poor families in comparison with those from sectors that are not poor. In the eight countries for which this information is available, attendance rates are lower among the poor, and the difference is particularly significant in Nicaragua, where the attendance rate of the poor is less than half that of the non-poor, and in El Salvador, Brazil and Ecuador, in all of which the gap is over $25 \%$.

Taking the countries analysed as a whole, the greatest disparity is between urban and rural areas. Urban attendance rates are significantly higher than rural ones, and once again the largest gaps are found in Nicaragua, Honduras and El Salvador. Chile, Brazil and Costa Rica also show significant disparities in access to secondary education, however.
TABLE 2

Latin America (eight countries): Indices of inequity in access to intermediate education

(Ratios between secondary school enrolment rates)

\begin{tabular}{lccc}
\hline & Male/female & Poor/not poor & Urban/rural \\
\hline Chile & 0.99 & 0.89 & 1.44 \\
Brazil & 0.91 & 0.69 & 1.49 \\
Costa Rica & 0.99 & 0.80 & 1.40 \\
Peru & 1.04 & 0.93 & 1.15 \\
Ecuador & 0.98 & 0.72 & 1.32 \\
El Salvador & 1.15 & 0.66 & 1.67 \\
Honduras & 0.90 & 0.78 & 1.80 \\
Nicaragua & 0.89 & 0.46 & 2.11 \\
\hline
\end{tabular}

Source: Prepared by the authors on the basis of data from the World Bank (n/d). See footnote 6 .

To sum up, analysis of the data on changes in intermediate school enrolment rates allows two general conclusions to be advanced. The first is that a homogeneous analysis of the problem is very difficult to achieve. There are structurally different situations that require different conceptual and political approaches if they are to be understood and addressed. The second is that the scope for "easy" gains in school enrolment is no longer there. This is due to the changing socio-economic environment and to the specific characteristics of the sectors that need to be incorporated into education, requiring special measures. In the case of group 4 countries, it is also due to major shortcomings in the general process of economic and social development.

\section{III}

\section{Where is reform going in Latin America?}

The literature on secondary education reforms in Latin America has grown substantially over recent years, as

\footnotetext{
${ }^{6}$ To generate the data used, the authors drew on the following information sources: Brazilian Geographical and Statistical Institute (IBGE) (1995); Chile, Ministry of Planning and Cooperation (MIDEPLAN) (1992); Costa Rica, Encuesta de Inversión social (ENISO) (1993); Ecuador, Encuesta Nacional de Hogares sobre Medición de Niveles de vida (1994); El Salvador, Encuesta Nacional de Hogares sobre Medición de Niveles de vida (1995); Honduras, Encuesta Nacional de Hogares sobre Medición de Niveles de vida
}

a result of the transformation process itself. ${ }^{7}$ Although there has been a wealth of technical discussion, and diagnostic analyses stress the diversity and complexity of situations, educational reforms are guided by fairly

(1993); Peru, Encuesta Nacional de Hogares sobre Medición de Niveles de vida (1991) and Nicaragua, Encuesta Nacional de Hogares sobre Medición de Niveles de vida (1993).

${ }^{7}$ A recent seminar on this problem held by IIEP-Buenos Aires provided an opportunity to revise the existing analysis for the region as a whole. See particularly Braslavsky, org. (2001). 
homogeneous principles. The main focuses of discussion are structural change, curricular reform and changes in management style. Although all these aspects are closely linked, we shall deal with them separately in the interests of analytical clarity.

\section{Structural change}

Structural changes in the education system are associated with increases in the number of years of compulsory schooling and with considerations deriving from the cycles in the development of pupils' personalities. As the number of years of compulsory schooling increases, content that was traditionally intended for a minority comes to be universally disseminated. Meanwhile, the status of "student" -traditionally the preserve of the urban middle classescomes to belong to the entire youth population.

It is worth remembering that the strategy of providing the same compulsory, long-term schooling to everybody arose in the advanced capitalist countries after the war, at a time of very strong economic growth, full employment and universal social services provision, led in many countries by the State. Insofar as, from a socio-economic point of view, the trend was favourable to social equity, the debate about expanding education essentially turned around the problems raised by the need to deal successfully with the growing diversity of pupils. Again, this expansion took place in a context that was relatively stable and predictable as regards work organization models. This context, it should also be recalled, allowed for the emergence of planning ideas that, whatever their objective merits, provided a political and technical instrument for projecting rates and levels of educational demand on the basis of tendencies in the operation of the labour market.

With some delay, Latin America has followed this rising tendency in the number of years of compulsory schooling. According to a recent UNESCO study, all the countries in the region other than Bolivia and Nicaragua have now made at least the first stage of secondary education compulsory (Macedo and Katzkowicz, 2000). By contrast with the advanced countries, however, this extension of compulsory schooling is taking place in a context of rising social inequality, ${ }^{8}$ weakening development planning mechanisms and significant uncertainty about future human resources

\footnotetext{
${ }^{8}$ See the systematic studies that ECLAC has done on the subject of the social gap. The most recent of these is The Equity Gap: A Second Assessment (ECLAC, 2000).
}

needs. In short, Latin America is having to cope simultaneously with diversity and inequality, and to do so in a context where structural tendencies are generating great uncertainty and the risk of rising social exclusion. In these circumstances, it is reasonable to wonder whether it is possible to put in place uniform structures that are valid for the entire population, considering how significant the inequalities within many of the region's countries are.

Increasing compulsory schooling to nine or ten years in countries or in regions within a particular country where average school attendance is four or five years is a task that can scarcely be achieved in the space of one or two generations unless there is a rapid process of general growth and development with equity. If these conditions do not obtain, increasing the number of years of compulsory schooling may have at least two perverse effects. Firstly, there is the risk that those who only manage six or seven years of schooling will perceive that they have not even obtained their certificate of full basic schooling, and this in an environment where the symbolic and actual value of this certificate is very great. Secondly, increasing the number of years of compulsory schooling may result in a tendency to spread the learning of certain basic subjects over a greater number of years and to put off the moment at which these studies are embarked upon, so that pupils who are only in school for part of the cycle will learn less than they would have done in a shorter compulsory education cycle. New curriculum designs have sought to avoid this risk by reinforcing early basic learning, but the problem arises with the actual application of these designs and not with their theoretical formulation.

These risks obviously do not justify the adoption of the opposite alternatives (not increasing the number of years of compulsory schooling, or introducing structures that are differentiated by the opportunities of each social sector), which are also regressive, as they consolidate existing differences. We only wish to sound a warning about the great complexity of this situation and open a debate about the need to design strategies which take account of this complexity rather than ignoring it.

\section{Curricular reform}

The curricular reforms initiated in different countries in the region over recent years have focused on three main areas:

- the transition from organization by disciplines to organization by areas of knowledge, 
- the introduction of a new type of curricular content, relating in particular to the values and the new skills required to operate as effective citizens and producers,

- the introduction of greater opportunities for pupils to choose what subjects to learn about, and of orientation as a teaching method.

The justification for these changes has been much debated by educationalists. Organization by disciplines was called into question a long time ago, both from the epistemological point of view and in relation to the consequences for the organization and management of schools. The new skills (the ability to work in teams, solve problems, experiment, interact with those who are different, etc.) and the values that are part of citizenship training (solidarity, tolerance, respect for human rights) are taught not necessarily as part of a single discipline, but rather through transversal methods that also require profound alterations in curricular organization and teachers' working methods. As regards greater opportunity for choice in learning, this was introduced partly in response to the increasing diversity of pupils, partly to develop students' ability to "learn how to learn", which has been recognized as one of the basic skills for coping with the demands of lifelong learning (Braslavsky, org., 2001).

As regards curricular management, some countries have opted to produce basic content that is used everywhere and then give schools or local authorities greater or lesser autonomy to devise individual content. Others, by contrast, have focused on creating national standards. In respect of methodologies for deciding on curriculum content, significant progress has also been made in incorporating the demands of actors from outside the school system through different forms of consultation and participation.

Taking stock of all this, it can be said that the changes have resulted in substantial modernization of the contents of secondary school curricula. It is also generally agreed, however, that the impact of these changes on what is actually happening in schools has been much less than was hoped. What accounts for the "resistance" of traditional structures? Apart from the usual difficulties associated with any educational reform, and the fact that altering behaviour is always a slow process, it would seem that the difficulty of changing the actual performance of those involved in the learning process (teachers and students) derives from two factors that are beginning to have far more attention paid to them than in the past: an external factor, youth culture, and an internal factor, the working conditions and professional culture of teachers.

\section{a) Youth culture}

The relationship between school attendance, youth and culture has undergone very significant changes over the last three decades. Historically, at least in the Western world, being young was associated with being a student, and consequently school culture occupied an important place in youth culture. The most telling manifestation of this was the way youth movements were identified with student movements. This association has weakened. Recent studies agree that while the expansion of schooling has created students on a mass scale, this same process has increased the diversity among them. Studenthood has become less important in determining the features of youth culture, and the place of school has been usurped, in a way, by consumption and thus the market. ${ }^{9}$

But changes in the socio-economic environment are also producing major shifts in what access to schooling signifies. Access to secondary schooling is no longer accompanied by expectations of social mobility. For many young people, this access merely means a postponement of the uncertainty produced by a changeable, restrictive and segmented labour market. ${ }^{10}$ Furthermore, the new sectors entering this level of education for the first time are very ill-equipped for learning, which explains the high indices of failure found in these groups. Lastly, the considerable diversity of youth culture does rest on some common elements: the importance of the body, of music and of certain personalized forms of religion, the predominance of images, empathy with the use of new technologies (not necessarily with an understanding of their workings), the fundamental importance of emotions as an aspect of social relationships and the predominance of the present as the most important time dimension (Margulis and Urresti, 1998 and Barbero, 1998).

By way of contrast, the predominance of these factors highlights the waning importance of some key elements of the traditional school culture: the predominance of reading, respect for knowledge and systematic work, the deferment of gratification, and appreciation of the past as a heritage that has to be transmitted and of the future as a project for which it is necessary to prepare oneself.

\footnotetext{
${ }^{9}$ See Dubet and Martucelli (1999) and Tenti (2000).

${ }^{10}$ Among recent publications on intermediate education and the labour market, see Filmus (2001).
} 
The new curricular proposals thus have to measure up to a situation that is complex both socioeconomically and culturally. Having an education does not guarantee a place in society with prospects for social mobility, nor does it bring admittance to the symbolic worlds that carry prestige in the dominant youth culture. In response to the opportunities for socialization offered by school, the options pursued often assume a clearly alternative character. Much of the sociology of youth culture makes mention of the phenomenon of gangs, "tribes" or similar forms of association, involving the construction of an identity characterized by its opposition -sometimes violent- to the institutions of the system. This violent opposition is different from the politically motivated youth violence that arose in the 1960s. According to studies by some anthropologists: "Opting for tribes works -in part- as a way of dropping out, an alternative path in life, guided by other values, oriented in a different direction. It means abandoning the fight outright before it has begun, getting off the train before it sets off" (...) "The links among tribal youths are brief and fleeting, a kind of sociability of the provisional, a culture of instability dominated by the here and now and the lack of a future" (...) "Thence the aimlessness, the weight of immediate motivations, the determination not to go outside or beyond oneself, the looking out for one another with such self-protective urgency" and (...) "the rule of the emotions" (Margulis and Urresti, 1998).

The contributions made by anthropological studies of youth are an essential input for the design of new curriculum proposals. Anthropology, however, tends to postulate an adaptive discourse whose message is that we should learn from the young. There is a tension between this adaptive discourse and the pedagogical and political discourse, according to which the school curriculum must always have an intentional, voluntary content embodying what it is that adults wish to transmit to the young. This tension is not new. One of the peculiar characteristics of our times, however, is how little hegemony the dominant way of thinking seeks to exert and, in the case of Latin America, how much "social capital" has deteriorated, as manifested by low indices of trust in others and particularly in the representatives of the institutions responsible for social order.

There is a great deal of empirical evidence to confirm that indices of trust are low among citizens in general. Some recent findings show that this is equally true of teachers, who tend to share the mistrust of citizens in general towards the public institutions and social actors responsible for social cohesion.
This analysis opens the way for a discussion that is beyond the scope of the present work. It only seems relevant to mention here the importance of the cultural dimension in the design of secondary education curricula. This dimension is not confined to cognitive aspects alone but implies linkage among the cognitive, the emotional, the aesthetic and the social, involving not just students but, as we shall see in the following point, teachers as well. Some countries have already begun to introduce this approach in a systematic way. ${ }^{11}$

This greater cultural density in the design of secondary education curricula means accepting the tension between adaptation to the new cultural patterns that characterize the young and the transmission of a particular set of skills, values and attitudes that define the will of adults. In this respect, schools can legitimately adopt the character of a socialization space with certain "countercultural" characteristics where it is possible to learn what is not learnt outside of school.

\section{b) The situation and role of teachers}

Curricular changes and alterations in management styles entailing much greater independence for schools are forcing teachers to undertake what amounts to a veritable retraining. Their performance is being affected by changes in all areas. The content that they have to transmit has been renewed, and it is assumed that this will be a permanent process. Their work, traditionally individual and solitary, now has to be coordinated with colleagues as part of an institutional plan. Pupils reach the classroom with levels of educational preparedness very different from what they were in the past, and require personalized attention. Traditional teaching methods are not appropriate for imparting the new skills that form the renewed curriculum of secondary education, as these new skills are personality characteristics and cannot be taught using either the head-on methods or the rote learning of the past. ${ }^{12}$

\footnotetext{
${ }^{11}$ Leite Berger Jr., R. (2001). The situation is even more complex in culturally heterogeneous countries, such as the Andean countries and some Central American ones, where increased access to secondary schooling is bringing in the indigenous population with its different cultural and linguistic patterns.

${ }^{12}$ Regarding the teaching methods appropriate for citizenship training, it would be interesting to make a comparison between the demands that used to be created by loyalty to the nation State and the demands created by citizenship in the globalized society. Durkheim (1998) provided a lucid analysis of the first point when he associated citizenship training with religious rituals and the cognitive dimension. For current needs, these methods are incompatible with the idea of identity construction.
} 
What kind of position are teachers in, objectively and subjectively, to confront these new challenges? The information available in certain of the region's countries relates chiefly to working conditions, salaries, occupational training and, in some cases, career opportunities. By contrast, there is very little systematic information on how teachers view the different cultural dimensions, the new paradigms prevailing among the young and the new professional demands being made on them. There is one recent survey, though, which was conducted in Argentina among a nationally representative sample of primary and secondary school teachers, and which at least provides an idea of certain important characteristics of secondary school teachers and allows some working hypotheses to be formulated. ${ }^{13}$

Firstly, while teachers' living conditions are a factor that influences the mood with which they approach reform in the education system, this study shows that an even more significant factor is their perception of what has happened to their position in society over recent years. Thus, teachers who perceive that their living conditions have deteriorated lately, and that this deterioration is going to continue over the coming years, are the group that is hardest to mobilize around reform proposals. By contrast, those who perceive themselves as moving up in society are more willing to accept commitments in relation to these new challenges. This finding suggests that a social policy for teachers would also act as a good educational policy.

Secondly, the way teachers view youth values is becoming a factor of great importance. The survey reveals that the perception teachers have of the standards guiding youth behaviour is, in the main, quite a negative one. According to teachers, young people reveal only a weak grasp of fundamental values such as social commitment, tolerance, national identity, honesty, family feeling, responsibility, effort, duty and respect for their elders. This view of the young is remarkably consistent among teachers, irrespective of their age, sex or social position.

As regards cultural consumption and production patterns, teachers display a profile that is problematical to say the least, considering their role in transmitting culture and training the young in the new skills

\footnotetext{
${ }^{13}$ Although the situation of Argentine teachers may be different from that of other countries', it could also be argued that where the phenomena analysed by the survey are concerned (cultural patterns and consumption) the features detected there may be even more strongly marked in other countries (see UNESCO-IIEP, 2000).
}

associated with competitiveness and citizenship. Watching television is the most common pastime among them. Their predominant cultural practice is watching videos. Going to the cinema is next in importance. Only $40 \%$ read a newspaper every day. The percentages using electronic mail or the Internet are in single figures, while just $18 \%$ write on a computer. Such reading as they do is mostly of teacher training material.

The way teachers conceive of the aims of education shows that they regard its objective as being the formation of the whole personality. This increases the likelihood of conflict with pupils, as what teachers pursue is precisely that which most differentiates and distances them from those who are the object of these efforts. Educating for work or, in a more focused way, for the transmission of knowledge are options to which teachers attach a very low priority.

One of the basic problems of secondary education revolves around the issue of authority. The young have a deficit of "significant adults", a role which teachers cannot easily assume given the characteristics of their training and their patterns of conduct. The way curricula are structured by disciplines aggravates this problem, owing to the widespread use of itinerant teachers who cannot play an efficient part in guiding pupils because they spend so little time in the school. A number of countries in the region are trying to deal with this by encouraging the allocation of teachers or teams of teachers exclusively to one establishment and by pursing training policies that focus on the cultural acquirements of teachers as well as scientific and pedagogical refresher material.

Importance is now being given to some proposals formulated earlier in other ambits, regarding the need for major changes in teacher training policies based on two key ideas: training in teams within the establishment itself, and the introduction, along with the cognitive dimension of professional development, of other dimensions in which many of the emotional perceptions that teachers have of the young and of the new cultural paradigms are rooted.

\section{Changes in management styles}

The educational changes implemented in Latin America in the 1990s have brought general reforms in management styles: greater decentralization and autonomy for schools, evaluation of results, support for innovation and the introduction of competition mechanisms for the allocation of different types of support. These issues have been very intensely debated, 
and the lack of empirical information about the effects of the changes has often meant that proposals have had a predominantly ideological character. This is not the place to summarize the terms of this debate. ${ }^{14} \mathrm{We}$ merely wish to point out that the way these innovations are applied in secondary education has specific features that differ greatly from those found in basic or higher education. Thus, for example, results measurement systems are used more widely in basic education than in secondary education. Conversely, school autonomy and demands for the creation of institutional profiles seem to be more a feature of secondary education than of basic education.

Over and above these peculiarities, recent experience with reforms in management styles shows that the time has come to contextualize the processes of administrative reform. Two different types of situations can be distinguished:

i) The situation of private schools or State schools catering to middle- and high-income sectors. In these schools, experience seems to show that greater autonomy is a necessary but not sufficient condition for creating the dynamism needed to satisfy the new requirements. These schools already have a great deal of autonomy, and while their results are better than other schools', it is reasonable to suppose that this is due to factors other than the specific actions of these establishments. The need here is not to deregulate further, but to work on the pedagogical and cultural aspects referred to in the previous point.

ii) The situation of schools admitting sections of the population that are new to this level of education. The situation is more complicated in these establishments, since while autonomy is a necessary condition if the diversity of the population is to be catered to, many of the studies on the situation of disadvantaged populations indicate that one of their main characteristics is difficulty in planning. Establishing competition among plans as a management method in this sector means creating a situation in which the most disadvantaged sectors are required to act on the basis of what they are least well equipped for.

\section{IV}

\section{Some conclusions and proposals}

What we wish to do in this final section is to offer some suggestions for thinking about strategies for change in secondary education. These suggestions take as read the starting point of this article, which is the need to cope simultaneously with the demands of young people from poor families who are only now entering intermediate education and the needs of sectors that are already catered to, and that are demanding the transformation of traditional provision. Clearly there can be no question of providing the traditional education to the new sectors and altering it just for those already in the system. It is precisely in the need to deal with all this at the same time that the complexity of the current situation consists. In view of this, these suggestions can be organized around three propositions. The first of these emphasizes the need to come to grips with the complexity and heterogeneity of existing situations, and

${ }^{14}$ See Morduchowicz (2000) and Gajardo (1999). shun universal solutions. The second relates to policies for getting from current situations to the goals being aimed at. The third, lastly, focuses on the need to give priority to the pedagogical aspects of educational reform.

\section{The heterogeneity of strategies}

When the challenge of universalizing secondary education is considered, one question that necessarily arises is why a significant proportion of adolescents do not attend any educational establishment. It can be said that there are basically three configurations of phenomena that are instrumental in this.

Firstly, there is still a large shortfall in the supply of secondary education in the region. Because secondary schooling has traditionally been oriented towards a minority, large areas, particularly in the countryside, do not have the establishments available to receive ever larger numbers of these young people. 
A second factor are the obstacles that prevalent poverty and deficient living conditions represent for many young people. The 1990s saw already high levels of poverty worsen, while at the same time the vulnerability of middle- and low-income families increased, so that young people are increasingly having to share in the responsibilities involved in providing a livelihood for their families. For them, the urgent needs of the present take precedence over investments whose benefits will be appreciated only in the medium or long term.

Lastly, there is a significant mismatch between the formal characteristics of the educational supply and the actual performance of actors in the teaching process. There is widespread discontent among teachers, and also among pupils, who do not find school to be a place for socially significant learning.

The coexistence of these three factors means that the development of education policies aiming at the expansion of good-quality intermediate education needs to combine a wide range of actions. In principle, there needs to be a substantial increase in infrastructure investment, which may mean not so much the expansion of schools along traditional lines as alternative forms in which a prominent role could be played by new information technologies. In addition, education policies need to be tied in with other social policies, something that experience suggests is harder than might be expected. Lastly, pedagogical reform, changes in management styles and substantial modifications in the profile and role of teachers seem to be crucial if this objective is to be achieved.

Most of the region's countries are now developing plans and programmes that provide for this array of measures. The typology of countries presented in section II of this article is a reminder of the impossibility of devising single policies for the whole region. The Southern Cone countries (group 1) are, relatively speaking, the ones whose networks of establishments are least badly placed to provide comprehensive coverage to young people, who in turn are less likely to be prevented from attending school by household poverty than are their counterparts elsewhere in the region. In these countries, the emphasis should be on pedagogical reform, in response to growing demands for quality. Rising school attendance rates in group 2 and 3 countries show the positive impact of the policies being implemented to expand intermediate education. In these countries, though, and particularly in those of group 3, the precarious living conditions of many young people threaten to put a ceiling on educational expansion, which makes it particularly important to tie education policies in with social policies more generally. Lastly, the group 4 countries, whose main obstacle is that they do not have the minimum level of economic and social development needed to set in train the expansion of intermediate education, are in a position where they need to develop a set of education policies that can hardly owe much to the rest of the region's. On the contrary, the challenge of providing an education in conditions of widespread poverty calls for a creative exercise in which the pedagogical dimension must clearly be uppermost.

The countries should come to terms with this diversity of situations within their own borders. The challenges differ between urban and rural areas, and the strategies that need to be developed to deal with similar problems cannot be the same in large middleincome cities as in small impoverished towns. Even the countries that are best placed economically and socially have large sections of their populations living in extreme poverty. Again, promoting education in a poor community in a poor country is not the same as promoting it in a poor community in a high-income country. Nor do single policies for a whole country seem to be an option. Rising social heterogeneity will only worsen if it is ignored and uniform policies are applied.

Education policies, like social policies generally, now require more accurate diagnostic analysis that can capture the growing complexity of the situations in which action has to take place, and the ability to tie together a wide range of instruments as the needs of the specific case being dealt with dictate. Only a policy that is based on the recognition of diversity can ensure homogeneity of outcomes.

\section{Transition policies}

Analysis of educational transformation processes has revealed both their visible characteristics and their shortcomings. Recent experience would seem to suggest that one of the most significant shortcomings is the failure to pay sufficient attention to the difficulties involved in transitions from existing situations to the outcomes envisaged.

Such transitions are attended by characteristics that make some kind of specific treatment necessary. Thus, for example, we know from all the information provided by results measurement systems that secondary education is receiving, and will continue to receive for some years more, students who are seriously deficient in their understanding of the basic codes of reading, 
writing and arithmetic. ${ }^{15}$ We also know that teachers operate on the basis of views, corporate interests and professional traditions that will not be altered simply because their working conditions or the contents of study plans change. ${ }^{16}$ Curriculum designs, management styles and the structure of school provision cannot be the same at the outset of reform as at later stages. There thus seems to be a need to introduce the idea of transition policies that are valid for specific situations and for specific periods of time (transitional curriculum designs for cohorts of pupils coming into intermediate education or some form of it over the coming years, transitional qualifications, etc.).

Thinking about such transition policies would make it possible to improve on current options for educational change that are based on general reform or on innovations that are tried out in a small number of establishments before being applied everywhere.

\section{The pedagogical dimension}

The strategies for change implemented in the region seem to have reached a point where they need to give greater priority and pay greater attention to the pedagogical and cultural dimension if they are to translate into changes in learning processes and outcomes. There are two fundamental aspects to this. The first concerns teachers. Given the educational challenges that the region's countries are facing at a time of profound social change, the teacher's role cannot be underestimated or replaced by other learning inputs. The second aspect concerns pedagogy as a discipline. In addition to motivated, well equipped teachers working in institutions where they can develop as independent professionals, what are needed are teaching solutions that are appropriate to social and cultural contexts as complex as those found in the region.

In summary, the great question is how education can be provided in conditions of acute social inequity. In Latin America we have not developed a pedagogy that can provide us with working methodologies and techniques that are appropriate for solving the learning problems of poor, culturally heterogeneous populations. In the case of secondary teaching, the complexity is greater still because the pedagogical answers that are needed relate to adolescents and young people who are going through what is always a difficult and awkward period. Insofar as these problems have deep cultural roots, the answers will also be marked by the cultural context in which they are produced.

\section{Bibliography}

Barbero, J.M. (1998): Jóvenes: des-orden cultural y palimpsestos de identidad, in H. Cubides (ed.), Viviendo a toda. Jóvenes, territorios culturales y nuevas sensibilidades, Bogotá, Siglo del Hombre Editores.

Brazilian Geographical and Statistical Institute (IBGE) (1995): National Household Survey, Brazil.

Braslavsky, C. (org.) (2001): La educación secundaria ¿Cambio o inmutabilidad? Análisis y debate de procesos europeos y latinoamericanos contemporáneos, Buenos Aires, Editorial Santillana/International Institute for Educational Planning (IIEP).

Chile, Ministry of Planning and Cooperation (Mideplan) (1992): National Socio-economic Survey. CASEN, Santiago, Chile.

Costa Rica (1993): Social Investment Survey. ENISO, December 1992 to February 1993.

${ }^{15}$ See Laboratorio Latinoamericano de Evaluación de la Calidad de la Educación, UNESCO/OREALC (2000).

${ }^{16}$ The request for each establishment to produce a plan, which arose from the increased autonomy granted to schools, elicited different responses. Schools that already had the capacity to produce their own plans continued with this. Many others, however, did no more than copy texts produced by publishers. This resulted in homogenization based not on public-sector policies, but on the policies of certain publishers in the private sector. See González Lucini (2001).
Dubet, F. and D. Martucelli (1999): ¿En qué sociedad vivimos?, Buenos Aires, Editorial Losada.

Durkheim, E. (1998): Educación y pedagogía, Buenos Aires, Editorial Losada.

EClaC (Economic Commission for Latin America and the Caribbean) (2000): The Equity Gap: A Second Assessment, LC/G.2096, Santiago, Chile, May.

Ecuador (1994): Encuesta Nacional de Hogares sobre Medición de Niveles de Vida. SMS.

El Salvador (1995): Encuesta Nacional de Hogares sobre Medición de Niveles de Vida. LSMS.

Filmus, D. (2001): La educación media frente al mercado de trabajo: cada vez más necesaria, cada vez más insuficiente, in C. Braslavsky (org), La educación secundaria ¿Cambio o inmutabilidad? Análisis y debate de procesos europeos y latinoamericanos contemporáneos, Buenos Aires, Editorial Santillana/IIEP.

Gajardo, M. (1999): Reformas educativas en América Latina. Balance de una década, Partnership for Educational Revitalization in the Americas paper, No. 15, Santiago, Chile, Partnership for Educational Revitalization in the Americas (PREAL).

González Lucini, F. (2001): La educación como tarea humanizadora, Madrid, Anaya.

Honduras (1993): Encuesta Nacional de Hogares sobre Medición de Niveles de Vida. LSMS.

Kaztman, R. and P. Gerstenfeld (1990): The complexity of 
evaluating social development, CEPAL Review, No. 41, LC/ G.1631-P, Santiago, Chile, ECLAC.

Laboratorio Latinoamericano de Evaluación de la Calidad de la Educación, UNESCO/OREALC (United Nations Educational, Scientific and Cultural Organization/ UNESCo Regional Office for Education in Latin America and the Caribbean) (2000): Primer estudio internacional comparativo sobre lenguaje, matemática y factores asociados en tercer y cuarto grado, Hacia dónde va el gasto público en educación? Logros y desafios, vol. II, Políticas sociales series, No. 42, Santiago, Chile, ECLAC.

Leite Berger Jr., R. (2001): Enseñanza media: los desafíos de la inclusión, in C. Braslavsky (org.), La educación secundaria ¿Cambio o inmutabilidad? Análisis y debate de procesos europeos y latinoamericanos contemporáneos, Buenos Aires, Editorial Santillana/IIEP.

Macedo, B. and R. Katzkowicz (2000): Educación secundaria. Balance y prospectiva, Santiago, Chile, UNESCo Regional Office for Education in Latin America and the Caribbean (OREALC), August.
Margulis, M. and M. Urresti (1998): La construcción social de la condición de juventud, in H. Cubides (ed.), Viviendo a toda. Jóvenes, territorios culturales y nuevas sensibilidades, Bogotá, Siglo del Hombre Editores.

Morduchowicz, A. (2000): Intervención estatal, incentivos y desempeño educativo, Buenos Aires, IIEP.

Nicaragua (1993): Encuesta Nacional de Hogares sobre Medición de Niveles de Vida. LSMS.

Nun, J. (2000): Democracia, ¿gobierno del pueblo o gobierno de los políticos?, Buenos Aires, Fondo de Cultura Económica (FCE).

Peru (1991): Encuesta Nacional de Hogares sobre Medición de Niveles de Vida. LSMS.

Tenti, E. (2000): Una escuela para los adolescentes, Buenos Aires, United Nations Children's Fund (UNICEF)/Editorial Losada.

UNESCO/IIEP (2000): Los docentes y los desafíos de la profesionalización, Buenos Aires, December.

World Bank (n/d): Educational Change in Latin America and the Caribbean, Washington, D.C. (PDF document, www.birf.org). 